\title{
DIREITO À SAÚDE E DEMOCRACIA SANITÁRIA: EXPERIÊNCIAS BRASILEIRAS
}

Right to health and health democracy: Brazilian experiences

${ }^{1}$ Faculdade de Medicina, Universidade de São Paulo. São Paulo/SP, Brasil.

${ }^{2}$ Núcleo de Pesquisa em Direito Sanitário, Universidade de São Paulo. São Paulo/SP, Brasil.

Correspondência: Fernando Mussa Abujamra Aith.E-mail: fernando.aith@usp.br.

Recebido em: 06/03/2015. 


\section{Introdução}

O reconhecimento da saúde como direito de todos e dever do Estado, expresso de forma inequívoca pelos artigos $6^{\circ}$ e 196 da Constituição da República Federativa do Brasil de 1988 (CF/88), representou um passo ousado e importante dado pela sociedade brasileira no campo de proteção dos direitos sociais. O direito à saúde ganhou, a partir de 1988, um status constitucional forte, na medida em que foram detalhadas várias garantias formais a este direito no país.

A estratégia de reconhecer formalmente a saúde como um direito na Constituição é uma opção política e jurídica adotada pela sociedade brasileira com uma série de desdobramentos práticos. Desde 1988, o sistema jurídico brasileiro oferece às pessoas um conjunto de garantias para a efetivação concreta do direito à saúde, garantias estas que geram obrigações e consequências amplas na atuação dos poderes Executivo, Legislativo e Judiciário. Nesse sentido, a Constituição brasileira foi além do simples reconhecimento formal do direito à saúde. As principais garantias jurídicas ao direito à saúde estão fixadas na própria $\mathrm{CF} / 88$, por meio do detalhamento de diversos deveres do Estado para que o direito à saúde seja concretamente efetivado.

Dentre as garantias fundamentais expressas na $\mathrm{CF} / 88$, devem ser ressaltadas as que se referem à estruturação do sistema de saúde brasileiro e à definição de um conjunto de princípios e diretrizes que deve ser observado pelos governantes e pela sociedade brasileira para a proteção da saúde individual e coletiva. No que se refere ao dever do Estado, a CF/88 prevê que este tem o dever de organizar um Sistema Único de Saúde (SUS) capaz de oferecer ações e serviços públicos universais, igualitários, regionalizados, hierarquizados e integrais. O SUS deve, ainda, ser organizado de acordo com a diretriz de participação da comunidade, reforçando a ideia de que a democracia sanitária representa um dos alicerces para sua construção e seu funcionamento (artigos 196 e 198, CF/88).

Um dos grandes desafios de efetivação do direito à saúde no Brasil contemporâneo é justamente o de desenvolver a democracia sanitária no país, criando um ambiente capaz de garantir a participação da sociedade na tomada das decisões estatais estratégicas em saúde. Para o desenvolvimento e a implantação da democracia sanitária, é importante criar e consolidar instituições e processos juridicamente regulados que possibilitem a participação efetiva da sociedade nas decisões estatais em saúde.

O tema em debate deste número da Revista de Direito Sanitário lança luzes sobre aspectos relevantes da democracia sanitária brasileira, por meio de estudos aprofundados e muito bem relatados acerca de algumas experiências brasileiras de democracia sanitária. O conjunto dos artigos publicados oferece preciosas informações sobre o funcionamento concreto de algumas instituições e processos jurídicos formais de participação em saúde hoje vigentes no Brasil. 


\section{Direito à saúde e democracia sanitária}

A efetivação do direito universal, igualitário e integral à saúde, tal como preconizado por nossa Constituição, depende largamente da democracia sanitária, da participação dos cidadãos na definição dos contornos do direito à saúde e das garantias concretas que serão oferecidas a este direito.

A democracia sanitária, por sua vez, pressupõe que o Estado, para dar conta de seu dever constitucional de proteção do direito à saúde, crie, incentive e desenvolva um ambiente de ampla participação democrática da sociedade na tomada de decisões estatais em saúde.

Passados mais de 26 anos desde a promulgação da Constituição Federal, os desafios para a efetivação do direito à saúde tal como preconizado pela CF/88 ainda são enormes. Pesquisa Datafolha divulgada em 2014 mostra que 45\% dos brasileiros identificam a saúde como o principal problema do país. O instituto de pesquisa aponta ainda que $62 \%$ da população considera a saúde no Brasil como ruim ou péssima ${ }^{1}$. Esses dados mostram que ainda há um grande caminho a se percorrer para fazer com que a promessa do direito à saúde estabelecida em nossa $\mathrm{CF} / 88$ se torne uma realidade, a ser refletida no grau de satisfação que as pessoas têm com relação à saúde. Em outras palavras, os dados mostram como a efetivação do direito à saúde ainda está longe de ser uma realidade no Brasil, embora a $\mathrm{CF} / 88$ o reconheça como tal.

A insatisfação do brasileiro com a saúde pode ser demonstrada, ainda, pela quantidade de ações judiciais demandando saúde no Brasil. Dados do Conselho Nacional de Justiça apontam que atualmente existem 392 mil ações judiciais de saúde no país ${ }^{2}$. O ingresso de ação judicial demandando um direito é um importante e típico processo jurídico de democracia sanitária, na medida em que permite ao cidadão pedir ao Poder Judiciário que interceda contra uma lesão ou ameaça de lesão a um direito - no caso, o direito à saúde. Essas demandas contam, em grande parte, com uma atuação ativa de importantes instituições de proteção de direitos no Brasil, como a Defensoria Pública e o Ministério Público.

A complexidade de efetivação do direito à saúde decorre de múltiplos fatores, sendo um dos principais deles o fato de que o próprio conceito de saúde é amplo e sujeito a interpretações diversas. A imprecisão conceitual sobre o que é a saúde produz efeitos jurídicos importantes. Afinal, quais exatamente são os deveres do Estado no que se refere à proteção do direito à saúde? Considerando-se que os

\footnotetext{
${ }^{1}$ PESQUISA Datafolha realizada com 2.109 pessoas com idade acima de 16 anos, entrevistadas em 140 municípios de todas as regiões do país. Disponível em: <http://www1.folha.uol.com.br/ seminariosfolha/2014/03/1432478-datafolha-aponta-saude-como-principal-problema-dos-brasileiros. shtml>. Acesso em: 17 mar. 2015.

${ }^{2}$ CONSELHO NACIONAL DE JUSTIÇA. Relatórios de cumprimento da Resolução CNJ n. 107. Disponível em: <http://www.cnj.jus.br/images/programas/forumdasaude/demandasnostribunais.forumSaude.pdf >. Acesso em: 17 mar. 2015.
} 
serviços de saúde consomem quantias consideráveis do orçamento público estatal, e também que os conhecimentos científicos sobre saúde individual e coletiva podem ser bastante controversos, a decisão estatal sobre quais serviços e produtos serão oferecidos à população brasileira por meio do SUS é extremamente estratégica, já que define os contornos reais do direito à saúde no país. Igualmente estratégicas são as decisões estatais que regulam o setor de saúde suplementar privada tomadas na Agência Nacional de Saúde Suplementar (ANS), já que são estas decisões que obrigam (ou não) as operadoras de planos de saúde a oferecerem serviços médicos, odontológicos e hospitalares mínimos aos seus clientes.

A democracia sanitária, como princípio fundamentador do sistema de saúde brasileiro, impõe que a definição dos contornos do que se entende juridicamente por direito à saúde seja feita com participação da sociedade. Isso implica que a sociedade deve ser consultada e, na medida do possível, delibere diretamente sobre o que significa saúde e sobre qual será a amplitude da proteção a ser oferecida pelo Estado a este direito.

Em síntese, os contornos do significado da expressão direito à saúde em nosso país dependem concretamente de decisões estatais estratégicas, tomadas por agentes públicos que ocupam cargos nos três poderes do Estado. Em linhas gerais, ao Poder Legislativo compete produzir leis que orientem e organizem o sistema de saúde brasileiro, público e privado; ao Poder Executivo compete executar as referidas leis e colocar em prática políticas econômicas e sociais que respondam às necessidades de saúde no Brasil de acordo com os princípios constitucionais; e ao Poder Judiciário compete julgar, em última instância, os conflitos que tenham como base a defesa do direito à saúde.

Para existir, a democracia sanitária depende, dentre outros fatores, de um ambiente que possibilite uma efetiva participação da comunidade nas decisões de Estado tomadas pelos três Poderes. O direito contribui muito para a construção desse ambiente democrático, por meio da criação formal de instituições e processos jurídicos de participação democrática em saúde.

A evolução histórica do direito sanitário no Brasil demonstra um caminho progressivo de criação e utilização de instituições e processos de participação nas decisões estatais em saúde. As opções jurídico-institucionais adotadas pela sociedade brasileira para a efetiva participação da sociedade no campo da saúde devem ser constantemente objeto de estudos e reflexões. O Brasil vivenciou a criação jurídica e formal de diversas instituições e processos de participação da comunidade na construção do direito à saúde, tais como as conferências federal, estaduais e municipais de saúde, as audiências públicas, as consultas públicas, a possibilidade de se ingressar com ação judicial na defesa deste direito, entre outros. Convém agora nos debruçarmos sobre como anda, atualmente, a aplicação empírica desses instrumentos jurídicos de participação democrática em saúde. 


\section{Experiências brasileiras de democracia sanitária}

Para aprofundar o conhecimento que temos sobre as experiências concretas de democracia sanitária no Brasil, os artigos que compõem o Tema em Debate deste número da Revista de Direito Sanitário apresentam importantes informações e análises sobre alguns dos processos jurídicos e instituições de participação democrática em saúde que hoje estão formalmente criados no Brasil.

Trettel e Leão, no artigo Teoria e prática da participação na Agência Nacional de Saúde Suplementar, abordam de forma crítica a maneira como a participação da comunidade vem ocorrendo na ANS. Trata-se de um estudo relevante sobre os processos de participação criados na agência para que a sociedade possa participar de suas decisões estratégicas, notadamente da formulação de resoluções normativas e da definição de ações estratégicas no campo fiscalizatório. As autoras identificam de que forma foram criados e como estão funcionando alguns órgãos e processos de participação no âmbito da agência, explorando a forma como foram reguladas as consultas públicas, as audiências públicas, as câmaras técnicas, os grupos técnicos, a Câmara de Saúde Suplementar, a Ouvidoria e a Agenda Regulatória. Ao final, realizam criteriosa análise desses processos de participação, apontando caminhos para seu aperfeiçoamento.

O artigo de Rocha, Zioni e Caetano, por sua vez, relata um caso exemplar de advocacia sanitário. $\mathrm{O}$ texto aborda de que forma uma organização não governamental do Acre utilizou-se das instituições e dos processos jurídicos de participação hoje existentes no Brasil para a defesa de seus interesses específicos relacionados com a proteção do direito à saúde. Denominado Advocacia sanitária, cidadania e participação social: análise, histórico e conquistas da Associação dos Portadores de Hepatite do Acre, o artigo relata a trajetória da associação e demonstra as estratégias de advocacia sanitária utilizadas para forçar os três poderes do Estado a respeitarem os direitos dos portadores de hepatites no Acre. As autoras revelam, de forma detalhada, como o movimento de defesa do direito à saúde desse grupo utilizou-se de ações judiciais para forçar o Poder Judiciário a decidir em seu favor, bem como os caminhos de advocacia sanitária utilizados para influenciar o Poder Legislativo na aprovação de leis que ampliassem as garantias jurídicas associadas à proteção específica dos portadores de hepatites. Por fim, a experiência relatada revela como a associação se utiliza dos instrumentos jurídicos de democracia sanitária para que o Poder Executivo incorpore em suas políticas de saúde as demandas oriundas dela.

A terceira experiência relatada neste número da Revista de Direito Sanitário e que guarda relação com a democracia sanitária no Brasil refere-se ao papel do Ministério Público na construção do direito à saúde no país. De autoria de Oliveira, Andrade e Milagres, o artigo Ministério Público e políticas de saúde: implicações de sua atuação resolutiva e demandista analisa as possibilidades de contribuição do Ministério Público em favor da efetividade do direito à saúde, adotando uma original terminologia referente ao uso dos instrumentos de atuação judicial e extrajudicial. O artigo demonstra de que forma o Ministério Público de Minas Gerais prioriza instrumentos de ação extrajudicial 
como principal estratégia de defesa do direito à saúde, deixando evidente que a judicialização é uma medida de exceção no caso do Ministério Público de Minas Gerais.

As experiências trazidas neste número são valiosas para uma compreensão mais abrangente da democracia sanitária brasileira, ampliando a capacidade de análise sobre o seu atual estado da arte e sobre os possíveis caminhos que podem ser seguidos para o aperfeiçoamento constante das instituições e dos processos de participação da sociedade em decisões estatais de saúde, sejam elas do Poder Legislativo, do Poder Executivo ou do Poder Judiciário.

\section{Considerações finais}

No que se refere à ciência do direito, e em especial ao campo do direito sanitário, importa-nos hoje em dia compreender de que forma os Estados Democráticos de Direito constroem, organizam e executam seus sistemas jurídicos e seus sistemas de proteção de direitos sociais.

Assim, no campo do direito sanitário, além de verificar se o direito à saúde é democraticamente construído no que se refere aos contornos de seu reconhecimento legal (o que é saúde? Qual saúde o Estado deve proteger? Que serviços e produtos de saúde o Estado deve oferecer?), é fundamental, ainda, compreender de que forma este direito está concretamente regulado pelo sistema jurídico para fins de sua efetivação. As decisões estatais legislativas, executivas e judiciárias em saúde devem contar, assim, com o máximo de transparência e participação da sociedade.

Conhecer quais são as possiblidades de participação democrática nas decisões estatais em saúde é, portanto, um passo importante para que possamos compreender, aprofundar e ampliar os cânones de nossa democracia sanitária.

\section{Referências}

CONSELHO NACIONAL DE JUSTIÇA. Relatórios de cumprimento da Resolução CNJ n. 107. Disponível em: <http://www.cnj.jus.br/images/programas/forumdasaude/ demandasnostribunais.forumSaude.pdf $>$. Acesso em: 17 mar. 2015.

PESQUISA Data folha realizada com 2.109 pessoas com idade acima de 16 anos, entrevistadas em 140 municípios de todas as regiões do país. Disponível em: <http://www1.folha.uol.com. br/seminariosfolha/2014/03/1432478-datafolha-aponta-saude-como-principal-problemados-brasileiros.shtml>. Acesso em: 17 mar. 2015.

Fernando Aith - Professor Doutor do Departamento de Medicina Preventiva da Faculdade de Medicina da Universidade de São Paulo; Pesquisador e membro do Conselho Deliberativo do Núcleo de Pesquisa em Direito Sanitário da Universidade de São Paulo. Advogado. São Paulo/SP, Brasil. E-mail: fernando.aith@usp.br. 